\title{
Tobacco Smoking Kills Slowly, while Smoking on Oxygen Is a Burning Issue
}

\author{
Frank Rassouli Otto D. Schoch \\ Clinic for Pulmonology and Sleep Medicine, Cantonal Hospital St. Gallen, St. Gallen, Switzerland
}

Smoking tobacco not only causes chronic obstructive pulmonary disease (COPD), lung cancer or cardiovascular disease, associations well known to the public, but also a variety of other cancers (e.g. oral cavity, pharynx, oesophagus, stomach, pancreas, kidney or cervix) and other severe chronic diseases (e.g. psoriasis, cataract, macular degeneration, hearing loss, osteoporosis, stomach ulcers, miscarriage, birth defects, impotence or infertility) [1]. Tobacco dependence has to be treated as a prevalent disease, where prevention through tobacco control mechanisms is a priority of public health activities. Motivational support and pharmacotherapy are effective treatments for affected individuals [2].

Long-term oxygen therapy (LTOT) is a common treatment provided by pulmonologists and other specialties, mainly in the setting of severe COPD, where it improves survival and quality of life $[3,4]$ as well as other parameters. Burn injuries are an infrequent but potentially lifethreatening complication of LTOT and are mainly caused by open flames or sparks used when lighting cigarettes or other tobacco products $[5,6]$. Additionally, facial hair and the use of particular hair products have recently been identified as potential risk factors for LTOT-related burn injuries [7]. The role of electronic cigarettes as another risk factor for burn injuries is not well studied, but several accidents in this context have also been reported [8].

In a recent issue of Respiration, Carlos et al. [9] report their experience with smoking-related home oxygen burn injuries. Their aim was to quantify the morbidity and mortality of these events over a 6-year period by review-

\section{KARGER}

E-Mail karger@karger.com

www.karger.com/res ing the charts of all patients admitted to their large regional burn center with approximately 350 admissions per year. They could identify 55 patients over this period, of whom more than half had to be intubated. The in-hospital mortality rate was high $(\sim 15 \%)$. More than half had to be transferred to a higher level of care afterwards. Importantly, repeated burn injuries occurred in $\sim 15 \%$ of the patients. Nearly $80 \%$ were discharged with home oxygen, while only $13 \%$ had documented prior counselling for smoking cessation. Furthermore, in almost $30 \%$ of the cases, collateral damage had occurred with other persons also injured by the fire, including children.

This is one of the largest records of smoking-related home oxygen burn injuries. It clearly highlights the clinical importance of this underestimated hazard, which may be addressed insufficiently in daily practice. There is no doubt that smoking cessation and pulmonary rehabilitation are the first and most important evidencebased steps in the management for all stages of COPD [10]. However, nicotine addiction is characterized by a strong dependency, and those affected really need every support we can offer, including behavioral support, nicotine replacement, vareniclin and bupropion. Only then, LTOT should be considered, and some colleagues are strict enough to deny prescribing LTOT to current smokers altogether. We thus fully agree with the authors' conclusion that aggressive educational and smoking cessation efforts have to be undertaken to minimize this risk and also to increase the beneficial effect of supplemental oxygen. 


\section{References}

1 WHO: The smoker's body. http://www.who. int/tobacco/publications/health_effects/ smokersbody_en_fr.pdf?ua $=1$ (accessed February 6, 2016).

2 Palange P, Simonds AK: ERS Handbook of Respiratory Medicine, ed 2. Sheffield, European Respiratory Society, 2013.

3 Croxton TL, Bailey WC: Long-term oxygen treatment in chronic obstructive pulmonary disease: recommendations for future research: an NHLBI workshop report. Am J Respir Crit Care Med 2006;174:373.
4 Tanni SE, Vale SA, Lopes PS, Guiotoko MM, Godoy I, Godoy I: Influence of the oxygen delivery system on the quality of life of patients with chronic hypoxemia. J Bras Pneumol 2007;33:161.

5 Murabit A, Tredget EE: Review of burn injuries secondary to home oxygen. J Burn Care Res 2012;33:212-217.

-6 Sharma G, Meena R, Goodwin JS, Zhang W, Kuo YF, Duarte AG: Burn injury associated with home oxygen use in patients with chronic obstructive pulmonary disease. Mayo Clin Proc 2015;90:492.

$>7$ Anderson BW, Greenlund AC, Greenlund LJ: Facial hair: a newly identified, modifiable risk factor in home oxygen therapy-related burns. Mayo Clin Proc 2014;89:1164.
Lacasse Y, Légaré M, Maltais F: E-cigarette use in patients receiving home oxygen therapy. Can Respir J 2015;22:83-85.

9 Carlos WG, Baker MS, McPherson KA, Bosslet GT, Sood R, Torke AM: Smoking-related home oxygen burn injuries: continued cause for alarm. Respiration 2016;91:151-155.

10 Global Initiative for Chronic Obstructive Lung Disease (GOLD): Global strategy for the diagnosis, management, and prevention of COPD. 2016. http://www.goldcopd.org/. 